\title{
Research on the Risk of the Fourth Party Logistics Enterprise Based on the Tripartite Cooperation Model under the Background of Made in China 2025: A Case Study of XCompany
}

\author{
HongyuLuo $^{1}$, JianfengWei ${ }^{2 *}, \mathrm{KeLi}^{3}$ \\ ${ }^{1}$ Institution of Auditing, Business School, Henan University,Kaifeng,China \\ ${ }^{2}$ Institutionof Business Administration, Henan University, Kaifeng, China \\ ${ }^{3}$ China Railway Construction Group Co.,Ltd., Beijing, China \\ *Corresponding Author.
}

\begin{abstract}
Under the background of "made in China 2025", China's logistics development ushered in new opportunities, which put forward newer and higher requirements for the transformation and upgrading of the logistics industry. The fourth party logistics enterprise is a supply chain integrator.At present, there is a kind of fourth party logistics enterprise based on tripartite cooperation and operation mode in China. That is, fourth party logistics enterprises combine transportation enterprises withinsurance companies, and meanwhile rely on logistics information platform to carry out safety management of freight vehicles. In fact, in the process of tripartite cooperation, there are many uncertain factors, which bring multiple risks to the fourth party logistics enterprises. This paper studies and analyzes the risks faced by the fourth party logistics enterprises, in order to determine the important risk factors, so as to provide decision-making reference for the fourth party logistics enterprises to avoid risks. Firstly, this paper identifies the specific risks in the environment, cooperation, finance and management of the tripartite cooperation model from the internal, external and partnership dimensions, and reveals the mechanism of the risks. Secondly, the analytic hierarchy process $(A H P)$ is used to calculate the comprehensive weight of each risk index, and the fuzzy synthetic evaluation method is used to determine the probability of risk. Finally, the overall risk level of X Company is obtained by establishing an evaluation matrix and weighting calculation according to the membership relationship between the evaluation matrix and the index weight. The results show that: from the perspective of the dimension of risk importance, cooperation risk and financial risk have the highest risk weight in the second-level index; in the third-level index, the behavioral risk of transportation enterprise, working capital risk and insurance company have the highest risk weight, while the weight of natural risk and political risk is lower. In the dimension of risk generation probability, inter-industry competition risk, transportation enterprise behavior risk, insurance company behavior risk and working capital risk are in the higher probability.
\end{abstract}

Keywords: Fourth party logistics, risk identification, risk assessment

\section{I.Introduction}

The fourth party logistics enterprise is a comprehensivemanagerof supply chain management, which has different operation modes. With the market-oriented reform of China's auto insurance rates, the tripartite cooperation mode relating to logistics enterprises, vehicle owners and insurance companies is emerging. Relying on the self-built logistics information platform, the fourth party logistics enterprises install remote terminal equipment on the freight vehicles, monitor and record the vehicle driving position, speed, driver's driving habits, driving status and other information in real time. Establishing a set of effective vehicle safety management scheme could effectively reduce the accident rate and insurance compensation rate of freight vehicles. Finally, the owners, insurance companies and logistics enterprises share the proceeds generated by the reduction of insurance loss ratio. Among these three partners, fourth party logistics enterprises face with multiple risks. It is significant to identify the risk factors for the healthy development of the fourth party logistics enterprises.

The study of the existing literature mainly focuses on the definition and performance research of the fourth party

ISSN: 0010-8189

(C) CONVERTER 2021

www.converter-magazine.info 
logistics. Gattorna believes that the fourth party logistics is the comprehensive manager of supply chain management, which establishes a complete set of supply chain management plans for the overall supply chain[1]. Cheng and Tang uses the hierarchical analysis method to establish a fourthparty logistics evaluation index system from the aspects of supply chain integration ability and information technology ability to evaluate its operational performance[2]. Other scholars (eg. Krakovics et al.;Buyukozkan et al.) evaluate the performance by using different methods of fourth party logistics[3,4]. Besides, some scholars also study the fourth party logistics risk. Hui et al mainly focuses on studying the Hong Kong air cargo industry, analyzes the relationship among the government, investors and users, and studies the revenue, cost and risk of the fourth party logistics platform[5]. Chinese scholars generally analyze it from the internal and external perspective of cooperation, macro and micro perspective, and the enterprise itself, cooperative relations and other aspects. Fu Shaochuan et al. discuss the behavior and generation mechanism of information risk[6]. Li Lijun and other scholars studied the moral risk problems existing in the supply chain after the signing of the contract and established a risk control model[7]. According to the agency theory, Tujun and Huang Min put forward the impact of third-party logistics on the quality risk of fourth party logistics due to information asymmetry and risk avoidance[8]. Chen Changbin and Chen Quan studied the credit relationship issues of the fourth party logistics advance and mortgage, and put forward the credit guarantee mechanism and reward and punishment measures based on the game theory. For the method of risk evaluation, because the risk itself has the characteristics of being difficult to accurately conduct data analysis, most scholars adopt the method of combining qualitative analysis and quantitative calculation in the process of risk evaluation[9]. Xiong Xiong et al. aimed at the credit risk generated in the supply chain finance, firstly selected various risk index data through the main component analysis, and then applied Logistic regression to calculate the credit status of each enterprise[10].

So far, there are relatively few risk researches of the fourth party logistics enterprises from the micro perspective, especially for the unique risk researches caused by the unstable cooperative relationship amongthe fourth party logistics enterprises, transportation enterprises and insurance companies under the new tripartite cooperation operation mode. This study identifies the unique risks in the environment, cooperation, finance and management under the tripartite cooperation mode from the internal, external and cooperative relationship dimensions, and reveals the risk mechanism. On this basis, the analytic hierarchy process is used to calculate the comprehensive weight of each risk index, and it also applies the fuzzy comprehensive evaluation method to determine the risk probability and estimates the overall risk level of X company.

\section{Risk Type Analysis}

This article focuses on the risks of fourthparty logistics corporations that adopt a tripartite cooperative operation mode, and summaries risk factors from internal and external dimensions. Firstly, it analyzes the political, economic, natural and horizontal competition factors in the external environment. Secondly, it analyzes the factors that threaten the stability of the cooperative relationship.Finally, some problems of the enterprise itself are discussed, including financial factors and management factors.

\subsection{Environmental risks}

In the daily operation of fourth party logistics corporations, macro external environmental risks play a vital role, which not only affects the company itself, but also indirectly affects fourth party logistics companies through its impact on cooperative companies. The environmental risks studied by this paper mainly include four aspects: politics, economy, nature and horizontal competition risk.

(1) Political risk. Changes in various policies, laws, and systems enacted by the government will make fourth party logistics companies face political risks to a certain extent. National policies are constantly changing according to economic development and international conditions, and these changes will bring huge uncertainties to the operating activities of enterprises. During Chinese industrial transformation period, policy changes are relatively frequently, and the impact of these changes on related industries is uncertain, especially the insurance industry. As environ- 
mental constraints and governance are intensified, the emission standards for automobile pollutants will inevitably increase, which will curb the number of freight vehicles. As a result, as an important party in the tripartite cooperation, transportation companies will face risks such as reduced vehicles and higher costs, which will affect the fourth party logistics corporations.

(2) Economic risks. Economic risk refers to the risk of economic losses for fourth party logistics companies affected by various macroeconomic factors, which mainly include factors such as the country's economic situation, changes in interest rates and exchange rates. The overall economic situation of the country shows cyclical fluctuations, and the upward and downward changes will have an impact on fourth party logistics companies. When the economy goes up, the number of transportation companies and their registered vehicles will increase significantly to meet a huge amount of cargo transportation demands. At the same time, insurance companies will vigorously develop their various insurance businesses and provide various preferential policies. When the economy goes down, the cargo transportation volume will be reduced, resulting in a decline in the number of transportation companies and vehicles, insurance companies will also shrink their business scales, and logistics companies' risks will increase.

(3) Natural risk. Natural risk refers to the risk of economic loss, which is resulted from business delays, interruptions, and forced terminations of the fourthparty logistics company and the other two parties of the cooperation caused by various uncertain, irresistible, and destructive disasters, including geological and climatic disasters such as earthquakes, typhoons, lightning, floods and fires. The losses caused by natural risk also has great uncertainty, which may be short-term, bearable, or lasting and devastating.

(4) Horizontal competition risk. The operation mode of the tripartite cooperation of the fourth party logistics is proposed in accordance with the background of the market-oriented reform of insurance premium rates. It is highly innovative, but as one of the many operation modes, it also faces great risks of horizontal competition. Innovative models are time-sensitive, and with the comprehensive completion of the market-oriented reform of insurance rates, more companies will adopt similar operating models in the face of such a huge freight vehicle insurance market. As a result, the market competition will be further intensified. With the rapid development of China's logistics industry, many foreign enterprises are gradually entering the competition in the domestic market. With sufficient funds, modern technology and advanced management, they will become strong competitors of domestic enterprises.

\subsection{Cooperation risks}

The stability of the cooperative relationship among logistics enterprises, transportation enterprises and insurance companies is the basis for the long-term existence of this model. The threats to the cooperative relationship mainly come from the availability of income, the rationality of income distribution, the behavior of transportation enterprises and the behavior of insurance companies.

(1) Income availability risk. The threat of profit availability risk to partnership is mainly due to the limitation of operation mode itself, which makes the gain of profit cannot be guaranteed. In the tripartite cooperation operation mode, the gain is the value backtracking caused by the reduction of accident rate, so that each partner can obtain additional benefits. For the new type of vehicle remote terminal equipment, the driver's understanding of the equipment function and proficiency in operation are directly affected by age and education level, some drivers may have a strong resistance to the equipment, so that the equipment cannot meet the ideal working effect.As a result, vehicle safety management cannot be well realized. In addition, freight vehicles are characterized by high risk, this kind of safety management is difficult to reduce or eliminate all risk factors, so it is impossible to guarantee an absolute decline in the accident rate, resulting in a reduction in the availability of income.

(2) Reasonable risk of income distribution. The demand object of the products of the fourth party logistics enterprises is the transportation enterprises, and the fourthparty logistics enterprises provide insurance products for the transportation enterprises. A buyer's market composed of transport companies is characterized by a wide range of sizes, 
ranging from a few dozen to tens of thousands of registered vehicles; the transportation enterprises have a wide variety of vehicles, such as heavy semi-trailer type, light, medium and heavy van-type, light, medium and heavy grid type, ordinary cargo type, special cargo type, self-unloading type, etc., the preference of vehicle owners varies greatly among transportation enterprises; the vehicles of various transportation enterprises travel in different areas, within and outside the province, as well as in the cold and harsh areas. In the face of the complex demand market, the fourth party logistics enterprises represent complicated income distribution calculation in the selection of transportation enterprises and in the process of determining the contract income distribution rate, which makes its rationality very controversial.

(3) Behavioral risks of transport enterprises. As there are a large number of small and medium-sized transport enterprises with low management level in the tripartite cooperation mode, the cooperation has great arbitrariness. Firstly, before the conclusion of the contract, the transportation enterprise will conceal the vehicle information that has adverse effects on it, so that the vehicles with high accident rate and poor road condition will be included in the operation mode of the tripartite cooperation. Secondly, after the signing of the contract, under the mentality of having insurance protection, driverswill reduce the control of safe driving behavior, oreven have immoral behavior, which will expand the degree of accident losses and greatly increase the accident rate of vehicles. Finally, the vehicles owned by transport enterprises are subjectively influenced by the vehicle owners to a large extent, vehicle owners' individual aspiration could also lead to the vehicle directly out of cooperation mode. The sudden exit of transportation enterprises and freight vehicles will not only bring the cost loss of on-board monitoring terminal equipment to the fourth party logistics enterprises, but also make the enterprises unable to obtain the profit sharing due to the reduction of the loss ratio.

(4) Behavioral risks of insurance companies. On the one hand, before signing the contract, the insurance company will its exaggerate management status and level of insurance service, so as to win the contract signed smoothly, but this will directly cause the fourth party logistics enterprisesto facedifficulties in communication, lack of insurance data resources, low level of insurance serviceand other problems in the process of cooperation with insurance companies, thus unable to establish a stable good relations of cooperation.On the other hand, the insurance company may unilaterally break off the cooperative relationship and choose other fourth party logistics enterprises with large number of vehicles, effective safety management and high management level, thus bringing huge losses to the fourth party logistics enterprises.

\subsection{Financial risks}

Financial risk refers to the risk of an enterprise in capital operation, that is, whether the supply of funds can meet the daily business activities, which is the basis of a long-term and stable operation of an enterprise, it mainly includes financing risk and working capital risk.

(1)Financing risk. Financing risks refer to the risks faced by enterprises when they raise funds from external banks, capital operation companies, private loans, or through the issuance of stocks and bonds. Firstly, due to the difference of the necessary rate of return, the amount of borrowing and the degree of difficulty, enterprises will face the uncertainty of the amount and the time of arrival when they raise funds from banks, fund operation companies and the private sector. Secondly, the government has strict requirements for issuing stocks and bonds, which must be approved by multiple departments, therefore, the success of issuing stocks and bonds is not certain. Financing risk is directly subject to the impact of enterprise operating conditions, enterprise scale and project development prospects. Due to the late emergence of the operation mode of tripartite cooperation, it is difficult for fund providers to compare similar operation modes and assess their development prospects in the financing process. Therefore, financing uncertainty is great. Finally, in the operation mode of tripartite cooperation, the fourth party logistics enterprises are required to invest a huge amount in the early stage of logistics information platform. Because of the large amount of funds to be raised, the financing difficulties and risks of enterprises are increased.

ISSN: 0010-8189

(C) CONVERTER 2021 
(2) Working capital risk. The enterprise in the daily business activities of the liquidity fund income and expenditure risk is the working capital risk. In the process of cooperation with transportation enterprises and insurance companies, the advance payment of insurance premium is the main source of working capital risks. If the recovery cycle of advance payment is too long, the amount of receivables is too large and the bad debt rate is too high, the amount of liquid funds will be reduced, thus increasing the financial risks of the enterprises. In addition, the income sharing at the end of the period is returned by the insurance company from the income of the loss ratio reduction, the timeliness and reliability of the payment of funds will also bring financial risks to the fourth party logistics enterprises.

\subsection{Management risks}

Management risk refers to the management pressure caused by the limitation of software and hardware management level of the fourth party logistics enterprises in the process of cooperation with different enterprises, it mainly includesthe reliability risk of information platform and human resource management risk.

(1) Reliability risk of information platform. The reliability risk of the information platform mainly refers to the risk arising from the security, stability and sustainability of the update of the logistics information platform. Logistics information platform is the transmission of information through the remote terminal equipment of vehicles and the Internet, so it faces the security threats in the Internet, including information theft, illegal invasion, system damage and so on. In addition, the operation of the logistics information platform is based on a huge scale of the backstage server, due to the unreasonable server design caused by the slow operation of the system, interruption and paralysis will affect the stability of the logistics information platform to a large extent. With the continuous development of technology, logistics information platform also needs to be constantly updated to adapt to the changing customer needs and more accurate vehicle safety management. Whether enterprises have the ability to continuously update is an important constraint.

(2) Human resource management risks. Talents are the key to the success of an enterprise, especially in important business departments, which need the support of personnel with professional abilities. The level of human resource management directly determines the stable operation and overall development process of an enterprise.Human resource management risks arise from whether the fourth party logistics enterprises can have qualified professional staff in time. Firstly, for the design and selection of freight vehicle insurance program personnel, it is necessary tohave freight vehicle insurance related theoretical basis and work experiencein orderto ensure the rationality of the insuranceprogram.Secondly, the operation and daily maintenance of the logistics information platform needpersonnel with relevant computer and information technology background.Finally, in the negotiation with transportation enterprises and insurance companies and further business development, we need personnel with certain marketing skills and interpersonal communication skills.

\section{Risk Generation Mechanism}

Environmental risk generation is complex. From the perspective of cooperation risk, financial risk and management risk generated within the supply chain operation and the enterprise, the deep-seated causes of risk are mainly reflected in three aspects.

\subsection{Constraints on the ability of the enterprise}

The subjective motivation of the actor is to pursue the optimal, but due to its own limitations, the realization of its goal is uncertain. In the process of tripartite cooperation, on the one hand, fourth party logistics (4PL) enterprises face the risks arising from their own limitations, on the other hand, the limitations of the cooperative enterprises will also pose a threat to the 4PL enterprises to a certain extent. 4PL enterprises in the availability of income, the rationality of income distribution, reliability of information platform and human resources management will be limited by their own ability. Firstly, the basis of income distribution is the reduction of insurance payout rate, so as to obtain the return of vehicle insurance premiums by insurance companies. Therefore, the realization of vehicle safety man-

ISSN: 0010-8189

(C) CONVERTER 2021 
agement is a crucial determinant. The authenticity and validity of vehicle information cannot be guaranteed because logistics enterprises are limited by their own ability and information acquisition cost. At the same time, the setting of vehicle safety management scheme is difficult to find the best solution. Secondly, as an important tool for the vehicle management of the 4PL enterprises, the safe and reliable operation of the logistics information platform is very important. However, because the platform itself has the characteristics of strong technological innovation, fast update speed and low security, considering the cost, technology and operator limitations, the reliability of the platform is difficult to be effectively guaranteed. Finally, the selection of insurance scheme is guided by professionals, which directly determines the incentive effect of insurance scheme on transport enterprises and the profits of enterprises. If the level of human resources management is limited, it cannot guarantee the rationality of insurance scheme selection.

Inadequate capacity of transport companies and insurance companies can also result in the availability of benefits that cannot be guaranteed. The reduction of vehicle accident rate is the source of the three-way revenue sharing. If the level of vehicle management of transport enterprises is not high, it is difficult to implement effective control of the vehicles to which they belong. Even if the 4PL enterprises provide effective vehicle management programs and personnel training, the effectiveness of vehicle safety management cannot guarantee.

\subsection{Information asymmetry}

(1) Adverse selection. In the tripartite cooperative relationship, transportation enterprises have the characteristics of different scale, different management level and different quality of enterprise personnel, so the authenticity and effectiveness of information sharing is greatly threatened, which makes the 4PL enterprises bear the huge risk of income distribution rationality and the risk caused by bad behavior of transport enterprises. Through the analysis of various types of historical information of vehicles which provided by transport enterprises, the 4PLinitially determines the level of its compensation rate, so as to choose the corresponding insurance scheme. The basics of vehicle security management is the basic information of vehicle, such as the vehicle type, the driving route, the frequency of accident, repairs, and the drivers' information. The security management of vehicles requires not only the real-time monitoring of the remote terminal unit, but also the determination of basic parameters according to the basic information of vehicles and matching safety management according to different vehicle conditions in order to reduce the accident rate effectively. The 4PL enterprises are in information disadvantage, when they are working with the transportation enterprises which provide the vehicles' information for them. Transportation enterprises are likely to hide some relevant information that is bad for themselves, and the information of distorted vehicles leads to lower insurance rates for vehicles with high accident rates. If the accident rate cannot be decreased efficiently by the security management of vehicles, the 4PLenterprises cannot achieve the goal of profit sharing with reduced compensation rate.Before the contracts are signed,the adverse selection of the insurance companies would bring behavior risks to the 4PL enterprises. Some insurance companies with low management level, poor service quality and lack of customers' resources are more motivated to join the tripartite cooperation model, thereby, they could expand business with the help of the 4PL corporation and gain advantages in vehicle resources.

(2) Moral hazard. Moral hazard is mainly due to the information asymmetry between the two parties, which leads to a series of self-interested behaviors after the establishment of the cooperative relationship, having adverse effects on the 4PL enterprises and causing heaving losses. The moral hazard faced by the 4PL enterprises comes from two aspects: transportation enterprisesand insurance companies.

The moral hazard of transportation enterprises would cause the working capital risk of the 4PL corporation and the behavior risk of transportation enterprises. Firstly,in the process of cooperation between the two parties, the 4PL enterprises will advance the insurance premium for the transportation enterprises. On the one hand, If the transportation enterprises conceal their poor financial situation, the 4PL enterprises will not be aware of the high risk of bad debts; on the other hand, the unethical behaviors of the transportation enterprises itself will cause the delay of repayment of advance payment, or even the abandonment repayment. Secondly, in order to pursue higher economic

ISSN: 0010-8189

(C) CONVERTER 2021 
concessions, or because of the subjective reasons of the vehicle owner, the transportation enterprises may terminate the cooperative relationship and directly withdraw from the cooperation model. The 4PL enterprises will not be able to get the gainsharing end-of-term and bear the economic loss of the remote terminal of the vehicle. Finally, because the signing of the insurance contract will enable the vehicle owner to get compensation after the accident, the owner will subjectively loosens the control of driving behavior and even takes some extreme behaviors to intentionally expand the severity of the accident, which greatly increases the insurance loss ratio.

The moral hazard of the insurance company is manifested in two aspects. Firstly, the insurance company conceals self-financial status and unethical behaviors, which will cause the return of the gainsharing end-of-term not being paid in time, or even being cancelled in payment, which will bring the working capital risk to the 4PL enterprises. Secondly, with the continuous development of cargo vehicle insurance business, there will be more and more enterprises engaged in the tripartite cooperation mode. Although limited by the contract, insurance companies may still not only seek for cooperation with other parties, but also take opportunistic behaviors to destroy the long-term cooperative relationship between the two parties and withdraw from the cooperation mode. Thus, the 4PL enterprises will suffer losses due to the interruption of cooperation.

\subsection{Asset specificity}

Williamson (divides specific assets into four types: site, physical assets, human assets and special purpose assets. The infrastructure and equipment of the logistics information platform belong to the physical assets, while the vehicles of a large number of transportation enterprises gathered by the 4PL enterprises belong to the special purpose assets.

In the tripartite cooperation mode, physical assets are mainly infrastructure and equipment of logistics information platform, including machine room, network server, information processing server and vehicle remote terminal equipment, etc. As the logistics information platform is a high-tech product, in order to ensure its safe and reliable operation, corporations not only have to cooperate with the international first-class enterprises with advanced technology, but also need to purchase equipment with brand recognition. Therefore, the investment in project design and equipment procurement will be extremely large. For the 4PL enterprise, the facilities and equipments required by logistics information platform have great asset specificity. Because the network server, the information processing server and the remote terminal equipment of the vehicle are customized according to the specific logistics information platform construction scheme, the possibility of these electronic equipments converted to other uses is very small and their depreciation rate is high which means companies sell them at a discount with low liquidity ratio. The higher specificity of assets makes the 4PL enterprises in a passive position in cooperation.

The vehicle resources owned by the 4PL enterprises are expressed as their special purpose assets. Since the insurance signing date of each transport vehicle is different, and according to the setting of the insurance scheme, the calculation cycle of income distribution is generally one year, and the return of income sharing is generally carried out after the expiration of the insurance, therefore, the 4PL enterprise and the basic insurance scheme aregenerally locked, it will be difficult to change once signed, this makes the insurance company grasp the initiative in a large extent, which will inevitably make the 4PL enterprises face rip-offs and insurance company behavior risk.

Table 1 Generation mechanism of various risk factors of the 4PL enterprises

\begin{tabular}{|c|c|}
\hline Risk factor & Generation Mechanism \\
\hline Environmental risk & Complicated mechanism(direct, indirect, random) \\
\hline Risk of income availability & Enterprise capability \\
\hline Reasonable risk of income distribution & Enterprise capability, information asymmetry \\
\hline Behavior risk of transportation enterprises & Enterprise capability, information asymmetry and asset specificity \\
\hline Behavior risk of insurance company & Enterprise capability, information asymmetry and asset specificity \\
\hline Financing risk & Asset specificity \\
\hline Working capital risk & Information asymmetry \\
\hline
\end{tabular}

ISSN: 0010-8189

(C) CONVERTER 2021 
Information platform reliability risk Human resource management risk
Enterprise capability Enterprise capability

\section{IV.Introduction and Business of the Fourth Party Logistics Company}

\subsection{Company profile}

X Company was invested and established in 2001, which is a modern integrated logistics enterprise that provides omni-directional and multi-functional logistics services. The company's car insurance program is mainly undertaken by its subsidiaries Y Company and Z Company. Founded in April 2012, Y Company is committed to providing intelligent logistics information services. Through the use of international advanced Internet, Internet of things, cloud platform and other technologies and management, Y provides modern logistics information services for all kinds of enterprises, so as to achieve a business model that combines innovative technology with business. For the efficient operation of Y Company's logistics information platform, Y Company contributed to the establishment of Z Company in May 2015, with a registered capital of 30 million RMB.Z Company(4PL enterprise) is an intelligent logistics information platform operator providing road transport industry chain services. Relying on the logistics information platform jointly built by international well-known high-tech enterprises such as IBM, INTEL and NEC, and introducing advanced methods such as big data, cloud computing and vehicle networking, Z Company integrates the forefront theory, knowledge and experience of supply chain integration and logistics management, and combine transportation enterprises, car owners, shippers, vehicle suppliers, accessories suppliers, vehicle service providers, financial institutions, insurance institutions and other users and related parties to integrate the advantageous resources owned by Z Company, so as to establish a perfect mutual transaction, communication and cooperation relationship between enterprises, and achieve win-win results.

\subsection{Basic business}

Y Company and Z Company (fourth Party Logistics Enterprise), together with a well-known insurance institution in China, put forward the "Zhixing Huitong" group vehicle insurance plan for Henan transportation enterprises, and created a new insurance cooperation model. This model uses the advanced vehicle networking technology of big data, cloud computing and mobile interconnection, relying on the advanced logistics information platform of $\mathrm{Z}$ Company and the vehicle risk management means and data resources of insurance companies, to provide basic vehicle insurance, major accident liability insurance, safety income sharing plan, safety management information and vehicle value-added services for standardized transport enterprises and logistics enterprises. The fourth party logistics enterprises install remote terminal equipment for the vehicles of transport enterprises to monitor the vehicle location information and related information in real time, and to improve driving behavior, reduce driving risk and optimize the path through the technical means of sending alarm information (overspeed, fatigue driving, dangerous areas and deviating from the route, etc.) to vehicle drivers. At the same time, the fourth party logistics enterprises provide information to help transport enterprises carry out fine management of vehicles, prevent and avoid safety accidents of transport vehicles.

This model can realize the win-win situation of the fourth party logistics enterprises, transportation enterprises and insurance companies. The benefit basis of tripartite cooperation is the additional benefits obtained by reducing the insurance compensation rate through vehicle safety management. In the tripartite cooperation mode, the fourth party logistics enterprises play a core role in preventing and avoiding safety accidents of transport vehicles and fine management of vehicles. As a result, transportation enterprises can improve their management level, enjoy insurance discounts and share the benefits; insurance companies can expand their business and share the profits. The sharing profit plans of the three parties are as follows:

(1)The transportation enterprise collects the detailed information of its own vehicle and provides it to the fourth party logistics enterprise.

ISSN: 0010-8189

(C) CONVERTER 2021 
(2)The fourth party logistics enterprises select the vehicle insurance scheme according to the basic information of the vehicle.

(3)The transportation enterprise takes out insurance in accordance with the insurance scheme provided by the fourth party logistics enterprise, and first enjoys the preferential payment of the early formalities jointly obtained by the fourth party logistics enterprise and the insurance company, and takes it as the insurance cycle on an annual basis.

(4) At the end of each year, the final profit shall be accounted for in accordance with the profit-sharing ratio agreed by the three parties. Shareable income $=$ total premium-preferential amount of upfront premium-operating cost of insurance institution-total amount of compensation during the contract period. The amount shared by all parties $=$ the benefits that can be shared $\mathrm{x}$ the proportion shared by all parties.

(5) According to the real-time monitoring and safety evaluation of the vehicle condition by the logistics information platform, the insurance scheme of the corresponding compensation rate and preferential policy in the next period is determined.

\section{Risk Assessment}

\subsection{Evaluation method}

According to the supply chain risk coordinate graph method proposed by Hallikas, the object of risk evaluation generally includes two dimensions: the degree of risk hazard and the probability of risk generation[11].This paper constructs the risk assessment combination matrix, as shown in Table 2. In this paper, firstly, according to the risk situation of Z Company, AHP is used to evaluate the risk hazard degree, and the comprehensive weight of each risk index is calculated by expert scoring to determine the hazard degree of various risks. Secondly, through the questionnaire survey of the relevant personnel of Z Company, the probability of risk generation is determined according to the evaluation grade standard of each risk index, thenthe evaluation matrix is established; Finally, according to the membership relationship between the evaluation matrix and the index weight, the weighted calculation is carried out, and the overall risk level of Z Company is obtained.

Table 2 Combination Matrix of Risk Assessment

\begin{tabular}{|c|c|c|c|c|c|}
\hline Probability of occurrence & Light & Lighter & Moderate & Heavier & Heavy \\
\hline Low & $\begin{array}{c}\text { Low-light } \\
\text { (low risk) }\end{array}$ & $\begin{array}{c}\text { Low-lighter } \\
\text { (low risk) }\end{array}$ & $\begin{array}{c}\text { Low-moder } \\
\text { ate } \\
\text { (Less risk) }\end{array}$ & $\begin{array}{c}\text { Low-heavy } \\
\text { (Less risk) }\end{array}$ & $\begin{array}{c}\text { Low-heavy } \\
\text { (average } \\
\text { risk) }\end{array}$ \\
\hline Lower & Low-light & $\begin{array}{c}\text { Low-light } \\
\text { (Less risk) }\end{array}$ & $\begin{array}{c}\text { Low-moder } \\
\text { ate } \\
\text { (Less risk) }\end{array}$ & $\begin{array}{c}\text { Low-heavy } \\
\text { (average } \\
\text { risk) }\end{array}$ & $\begin{array}{c}\text { Low-heavy } \\
\text { (high risk) }\end{array}$ \\
\hline Medium & (Less risk) & $\begin{array}{c}\text { Medi- } \\
\text { (Less risk) }\end{array}$ & $\begin{array}{c}\text { Me- } \\
\text { (average } \\
\text { risk) }\end{array}$ & $\begin{array}{c}\text { dium-heavy } \\
\text { (high risk) }\end{array}$ & $\begin{array}{c}\text { Medium-heavy } \\
\text { (high risk) }\end{array}$ \\
\hline Higher & $\begin{array}{c}\text { Higher-lighter } \\
\text { (Less risk) }\end{array}$ & $\begin{array}{c}\text { Higher-lighter } \\
\text { (average risk) }\end{array}$ & $\begin{array}{c}\text { High- } \\
\text { er-moderate } \\
\text { (high risk) }\end{array}$ & $\begin{array}{c}\text { High- } \\
\text { er-heavier } \\
\text { (high risk) }\end{array}$ & $\begin{array}{c}\text { High-heavy } \\
\text { (high risk) }\end{array}$ \\
\hline Thigh-light & $\begin{array}{c}\text { High-light } \\
\text { (high risk) }\end{array}$ & $\begin{array}{c}\text { High-moder } \\
\text { ate } \\
\text { (high risk) }\end{array}$ & $\begin{array}{c}\text { High-heavy } \\
\text { (high risk) }\end{array}$ & $\begin{array}{c}\text { High-heavy } \\
\text { (high risk) }\end{array}$ \\
\hline
\end{tabular}

\subsection{Risk indicators and weights}

The author investigated 15 experts in the industry by questionnaire, including senior managers of the fourth party logistics enterprises and logistics scholars. By using the method of expert scoring, the importance of each index at the

ISSN: 0010-8189 
next level of each risk index is compared in pairs, and the importance is assigned. The hierarchical diagram of risk indicators of the fourth party logistics enterprises is shown in Figure1.

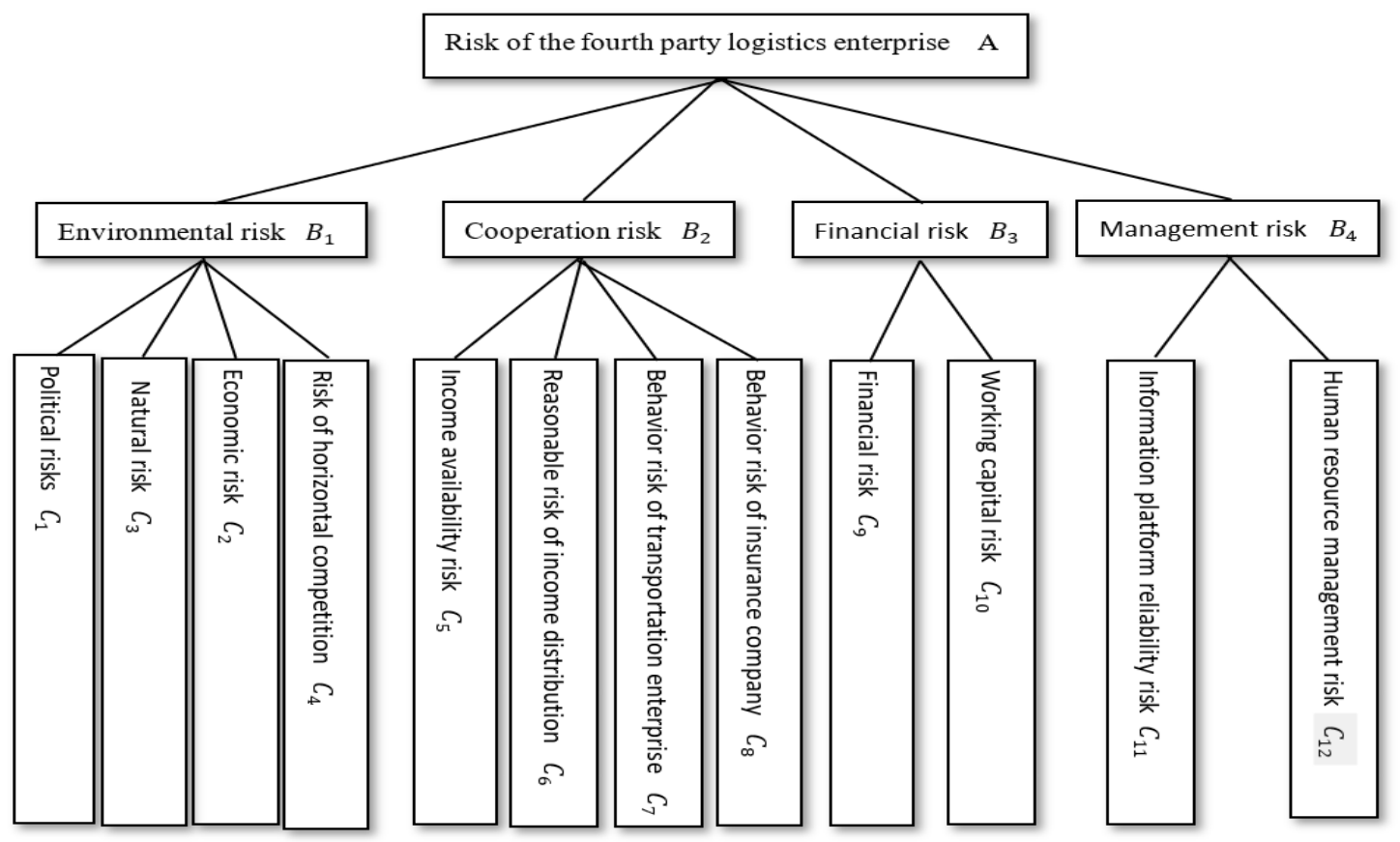

Figure 1 Hierarchy diagram of the risk indicators of the fourth party logistics enterprises

According to the expert rating, the weight calculation results are obtained, as shown in Table 3, Table 4, Table 5, Table 6 and Table 7. The values of all the calculation results $\operatorname{are}_{R}<0.1$, which meets the requirements of consistency.

Table 3Weight Table of Secondary Indicators

\begin{tabular}{|c|c|c|c|c|c|c|c|}
\hline \multicolumn{5}{|c|}{ Judgment matrix } & \multirow{2}{*}{$\begin{array}{c}\text { Index weight } \\
\text { W }\end{array}$} & \multirow{2}{*}{$\lambda_{\max }$} & \multirow{2}{*}{$C_{R}$} \\
\hline $\mathrm{A}$ & $B_{1}$ & $B_{2}$ & $B_{3}$ & $B_{4}$ & & & \\
\hline$B_{1}$ & 1 & $1 / 6$ & $1 / 5$ & 2 & 0.0870 & \multirow{4}{*}{ 4. 0693} & \multirow{4}{*}{0.0260} \\
\hline$B_{2}$ & 6 & 1 & 2 & 7 & 0.5191 & & \\
\hline$B_{3}$ & 5 & $1 / 2$ & 1 & 6 & 0.3372 & & \\
\hline$B_{4}$ & $1 / 2$ & $1 / 7$ & $1 / 6$ & 1 & 0.0567 & & \\
\hline
\end{tabular}

Table 4 Weight table of three-level indicators

\begin{tabular}{|c|c|c|c|c|c|c|c|}
\hline \multicolumn{5}{|c|}{ Judgment matrix } & \multirow{2}{*}{$\begin{array}{c}\text { Index weight } \\
\mathrm{W}\end{array}$} & \multirow{2}{*}{$\lambda_{\max }$} & \multirow{2}{*}{$C_{R}$} \\
\hline$B_{1}$ & $C_{1}$ & $C_{2}$ & $C_{3}$ & $C_{4}$ & & & \\
\hline$C_{1}$ & 1 & $1 / 5$ & $1 / 2$ & $1 / 6$ & 0.0634 & \multirow{4}{*}{ 4. 1323} & \multirow{4}{*}{0.0496} \\
\hline$C_{2}$ & 5 & 1 & 4 & $1 / 3$ & 0.2858 & & \\
\hline$C_{3}$ & 2 & $1 / 4$ & 1 & $1 / 5$ & 0.0985 & & \\
\hline$C_{4}$ & 6 & 3 & 5 & 1 & 0.5523 & & \\
\hline
\end{tabular}

Table 5 Weight table of three-level indicators

\begin{tabular}{|c|c|c|c|c|c|c|c|}
\hline \multicolumn{5}{|c|}{ Judgment matrix } & \multirow{2}{*}{$\begin{array}{c}\text { Index weight } \\
\mathrm{W}\end{array}$} & \multirow{2}{*}{$\lambda_{\max }$} & \multirow[b]{2}{*}{$C_{R}$} \\
\hline$B_{2}$ & $C_{5}$ & $C_{6}$ & $C_{7}$ & $C_{7}$ & & & \\
\hline$C_{5}$ & 1 & 2 & $1 / 5$ & $1 / 4$ & 0.0971 & \multirow{2}{*}{ 4. 1072} & \multirow{2}{*}{0.0402} \\
\hline$C_{6}$ & $1 / 2$ & 1 & $1 / 7$ & $1 / 5$ & 0.0596 & & \\
\hline
\end{tabular}

ISSN: 0010-8189

(C) CONVERTER 2021 


\begin{tabular}{|l|l|l|l|l|l|l|l|}
\hline$C_{7}$ & 5 & 7 & 1 & 3 & 0.5621 & & \\
\hline$C_{8}$ & 4 & 5 & $1 / 3$ & 1 & 0.2812 & & \\
\hline
\end{tabular}

Table 6 Level 3 Index Weight Table

\begin{tabular}{|c|c|c|c|c|c|}
\hline \multicolumn{3}{|c|}{ Judgment matrix } & \multirow{2}{*}{$\begin{array}{c}\text { Index weight } \\
\mathrm{W}\end{array}$} & \multirow{2}{*}{$\lambda_{\max }$} & \multirow{2}{*}{$C_{R}$} \\
\hline$B_{3}$ & $C_{9}$ & $C_{10}$ & & & \\
\hline$C_{9}$ & 1 & $1 / 5$ & 0.1667 & \multirow{2}{*}{ 2. 0000} & \multirow{2}{*}{0.0000} \\
\hline$C_{10}$ & 5 & 1 & 0.8333 & & \\
\hline
\end{tabular}

Table 7 Level 3 Index Weight Table

\begin{tabular}{|c|c|c|c|c|c|}
\hline \multicolumn{3}{|c|}{ Judgment matrix } & \multirow{2}{*}{$\begin{array}{c}\text { Index weight } \\
\text { W } \\
\end{array}$} & \multirow{2}{*}{$\lambda_{\max }$} & \multirow{2}{*}{$C_{R}$} \\
\hline$B_{4}$ & $C_{11}$ & $C_{12}$ & & & \\
\hline$C_{11}$ & 1 & 2 & 0.6667 & \multirow{2}{*}{2.0000} & \multirow{2}{*}{0.0000} \\
\hline$C_{12}$ & $1 / 2$ & 1 & 0.3333 & & \\
\hline
\end{tabular}

According to the calculation results of relative weight of risk indicators, the comprehensive weight of the hazard degree of each risk indicator on the overall risk impact of the enterprise can be obtained. The calculation results are shown in Table 8 and Table 9.

Table 8 Comprehensive weight of three-level indicators

\begin{tabular}{|c|c|c|c|c|c|}
\hline & $\mathrm{B}_{1}(0.0870)$ & $\mathrm{B}_{2}(0.5191)$ & $\mathrm{B}_{3}(0.3372)$ & $\mathrm{B}_{4}(0.0567)$ & Comprehensive weight \\
\hline$C_{1}$ & $0.0634 \times B_{1}$ & - & - & - & 0.0055 \\
\hline$C_{2}$ & $0.2858 \times \mathrm{B}_{1}$ & - & - & - & 0.0249 \\
\hline$C_{3}$ & $0.0985 \times \mathrm{B}_{1}$ & - & - & - & 0.0086 \\
\hline$C_{4}$ & $0.5523 \times \mathrm{B}_{1}$ & - & - & - & 0.0481 \\
\hline$C_{5}$ & - & $0.0971 \times B_{2}$ & - & - & 0.0504 \\
\hline$C_{6}$ & - & $0.0596 \times \mathrm{B}_{2}$ & - & - & 0.0309 \\
\hline$C_{7}$ & - & $0.5621 \times \mathrm{B}_{2}$ & - & - & 0.2918 \\
\hline$C_{8}$ & - & $0.2812 \times \mathrm{B}_{2}$ & - & - & 0.1460 \\
\hline$C_{9}$ & - & - & $0.1667 \times \mathrm{B}_{3}$ & - & 0.0561 \\
\hline$C_{10}$ & - & - & $0.8333 \times \mathrm{B}_{3}$ & - & 0.2810 \\
\hline$C_{11}$ & - & - & - & $0.6667 \times \mathrm{B}_{4}$ & 0.0378 \\
\hline$C_{12}$ & - & - & - & $0.3333 \times \mathrm{B}_{4}$ & 0.0189 \\
\hline
\end{tabular}

Table 9 Comprehensive weight ranking of three-level indicators

\begin{tabular}{|c|c|c|c|}
\hline Serial number & Risk indicators & Level number & Weight \\
\hline 1 & Behavior risk of transportation enterprise & $C_{7}$ & 0.2918 \\
\hline 2 & Working capital risk & $C_{10}$ & 0.2810 \\
\hline 3 & Behavioral risk of insurance companies & $C_{8}$ & 0.1460 \\
\hline 4 & Financing risk & $C_{9}$ & 0.0561 \\
\hline 5 & Income availability risk & $C_{5}$ & 0.0504 \\
\hline 6 & Risk of horizontal competition & $C_{4}$ & 0.0481 \\
\hline 7 & Information platform reliability risk & $C_{11}$ & 0.0378 \\
\hline 8 & Reasonable risk of income distribution & $C_{6}$ & 0.0309 \\
\hline 9 & Economic risk & $C_{2}$ & 0.0249 \\
\hline 10 & Human resource management risk & $C_{12}$ & 0.0189 \\
\hline 11 & Natural risk & $C_{3}$ & 0.0086 \\
\hline 12 & Political risk & $C_{1}$ & 0.0055 \\
\hline
\end{tabular}


5.3Assessment of the overall risk level of X company

As for the probability of risk generation, this paper conducted a questionnaire survey on 20 related persons of $\mathrm{X}$ Company, mainly including department heads, grass-roots employees and experts in related fields, etc., evaluated each risk indicator according to the risk generation probability evaluation standard of the fourth party logistics enterprises, summarized the questionnaire results (Table 10), and obtained the evaluation matrix. For example, for risk indicator, if 9 people are judged to be low risk, 8 people are judged to be low risk, 2 people are judged to be medium risk, 1 person is judged to be high risk, and 0 people are judged to be high risk, then the evaluation set $R_{C_{1}}=$ $(9 / 20,8 / 20,2 / 20,1 / 20,0)$.

Table 10 Evaluation Results Table

\begin{tabular}{|c|c|c|c|c|c|c|}
\hline \multirow{2}{*}{$\begin{array}{c}\text { Level num- } \\
\text { ber }\end{array}$} & Risk indicators & \multicolumn{3}{|c|}{ Opinion rating } \\
\cline { 3 - 6 } & Political risk & $\begin{array}{c}\text { Low } \\
\text { risk }\end{array}$ & $\begin{array}{c}\text { Lower } \\
\text { risk }\end{array}$ & $\begin{array}{c}\text { Medium } \\
\text { risk }\end{array}$ & $\begin{array}{c}\text { Higher } \\
\text { risk }\end{array}$ & High-risk \\
\hline$C_{1}$ & Economic risk & 9 & 8 & 2 & 1 & 0 \\
\hline$C_{2}$ & Natural risk & 11 & 7 & 2 & 0 & 0 \\
\hline$C_{3}$ & Risk of horizontal competition & 1 & 1 & 9 & 7 & 2 \\
\hline$C_{4}$ & Income availability risk & 1 & 5 & 9 & 4 & 1 \\
\hline$C_{5}$ & Reasonable risk of income distribu- \\
tion & 2 & 9 & 8 & 1 & 0 \\
\hline$C_{6}$ & Behavior risk of transportation en- \\
terprise & 0 & 2 & 5 & 8 & 5 \\
\hline$C_{7}$ & Behavior risk of insurance compa- \\
ny & 1 & 3 & 6 & 7 & 3 \\
\hline$C_{8}$ & Financing risk & 6 & 8 & 4 & 2 & 0 \\
\hline$C_{9}$ & Working capital risk & 1 & 4 & 4 & 7 & 4 \\
\hline$C_{10}$ & Information platform reliability risk & 4 & 6 & 7 & 2 & 1 \\
\hline$C_{11}$ & Human resource management risk & 7 & 8 & 4 & 1 & 0 \\
\hline$C_{12}$ & & & & & \\
\hline
\end{tabular}

$$
\begin{array}{r}
R_{B 1}=T_{B 1} \cdot B_{1}=(0.0634,0.2858,0.0985,0.5523) \times\left[\begin{array}{ccccc}
9 / 20 & 8 / 20 & 2 / 20 & 1 / 20 & 0 \\
3 / 20 & 4 / 20 & 10 / 20 & 2 / 20 & 1 / 20 \\
11 / 20 & 7 / 20 & 2 / 20 & 0 & 0 \\
1 / 20 & 1 / 20 & 9 / 20 & 7 / 20 & 2 / 20
\end{array}\right] \\
=(0.15319,0.14461,0.407625,0.225055,0.06952)
\end{array}
$$

$$
R_{B 2}=T_{B 2} \cdot B_{2}=(0.0971,0.0596,0.5621,0.2812) \times\left[\begin{array}{ccccc}
1 / 20 & 5 / 20 & 9 / 20 & 4 / 20 & 1 / 20 \\
2 / 20 & 9 / 20 & 8 / 20 & 1 / 20 & 0 \\
0 & 2 / 20 & 5 / 20 & 8 / 20 & 5 / 20 \\
1 / 20 & 3 / 20 & 6 / 20 & 7 / 20 & 3 / 20
\end{array}\right]
$$$$
=(0.024875,0.149485,0.29242,0.34566,0.18756)
$$

$$
R_{B 3}=T_{B 3} \cdot B_{3}=(0.1667,0.8333) \times\left[\begin{array}{ccccc}
6 / 20 & 8 / 20 & 4 / 20 & 2 / 20 & 0 \\
1 / 20 & 4 / 20 & 4 / 20 & 7 / 20 & 4 / 20
\end{array}\right]
$$$$
=(0.091675,0.23334,0.2,0.308325,0.16666)
$$

$$
R_{B 4}=T_{B 4} \cdot B_{4}=(0.6667,0.3333) \times\left[\begin{array}{ccccc}
4 / 20 & 6 / 20 & 7 / 20 & 2 / 20 & 1 / 20 \\
7 / 20 & 8 / 20 & 4 / 20 & 1 / 20 & 0
\end{array}\right]
$$




$$
\begin{gathered}
R_{A}=T_{A} \cdot A \\
=(0.0870,0.5191,0.3372,0.0567) \times\left[\begin{array}{ccccc}
0.15319 & 0.14461 & 0.407625 & 0.225055 & 0.06952 \\
0.024875 & 0.149485 & 0.29242 & 0.34566 & 0.18756 \\
0.091675 & 0.23334 & 0.2 & 0.308325 & 0.16666 \\
0.249995 & 0.33333 & 0.300005 & 0.083335 & 0.033335
\end{array}\right] \\
=(0.071327669,0.1877607925,0.2717088805,0.3077041755,0.1614984825)
\end{gathered}
$$

According to the principle of maximum membership degree, the higher risk corresponding to the evaluation result of 0.3077041755 is the overall risk level of Z Company.

According to the comprehensive weight of the hazard degree of risk indicators, cooperation risk and financial risk are the indicators with the greatest hazard degree in the second level, with weights of 0.5191 and 0.3372 respectively; In the third level, the risk indicators with higher degree of risk harm are transportation enterprise behavior risk, working capital risk and insurance company behavior risk, and the corresponding comprehensive weights are $0.2918,0.2810$ and 0.1460 respectively. It can be seen from the survey results of risk assessment probability that nearly half of the people think that the risk indicators with higher probability are horizontal competition risk, transportation enterprise behavior risk, insurance company behavior risk and working capital risk. To sum up, the overall risk ofXCompany is at a high level, which is mainly due to the high behavioral risk of transportation enterprises and insurance companies, which leads to the high level of cooperation risk. In addition, as an important factor affecting financial risk, working capital risk is at a high level, which needs to be paid enough attention to.

\section{VI.Conclusion}

1. The tripartite cooperation mode led by the fourth party logistics enterprises is a mixed operation mode of information sharing and value-added services. The insurance products provided by the fourth party logistics enterprises are value-added services to meet the personalized needs of transportation enterprises, which not only improve the safety of freight vehicles, but also enable them to obtain considerable premium reduction benefits.

2. In the process of tripartite cooperation, fourth party logistics enterprises are faced with the risk of political, economic, natural and peer competition in the external environment due to bounded rationality, information asymmetry, and asset specificity.The availability of income, the rationality of income distribution and the behavior risk of transportation enterprise and insurance company threaten the cooperative relationship.In addition, there are financial risks of insufficient financing and working capitalshortage risks, information platform reliability risksand human resource management risks determined by the management level.

3. By applying the risk assessment system to ZCompany, it is concluded that its overall risk is at a relatively high level. In the dimension of risk hazard degree, the cooperation risk and financial risk at the second level have higher hazard degree, and the behavior risk of transportation enterprise, working capital risk and insurance company behavior risk at the third level have the greatest impact on the overall risk of the company. In the dimension of risk probability, inter-industry competition risk, transportation enterprise behavior risk, insurance company behavior risk and working capital risk have higher probability.

\section{Reference}

[1] J.Gattorna, "Strategic supply chain alignment," Hampshire: Gower Publishing Limited,1998.

[2] J.H.Cheng, C.H.Tang, “An application of fuzzy Delphi and fuzzy AHP for multi-criteria evaluation model of fourth party logistics, WSEAS Transaction on Systems, vol.7, no.5, pp. 466-478, 2008.

[3] F.Krakovics,J.E.Leal, P.M.Jr, R.L.Santos, "Defining and calibrating performance indicators of a 4PL in the chemical industry in Brazil,'International Journal of Production Economics, vol.115, no.2, pp.502-514, 2008.

[4] G.Büyüközkan, O.Feyzioğlu, M.S. Ersoy,"Evaluation of 4PL operating models: A decision making

ISSN: 0010-8189

(C) CONVERTER 2021 
approach based on 2-additive Choquet integral,'International Journal of Production Economics, vol. 121, no.1,pp.112-120,2009.

[5] Y.V.Hui,L.C.Leung,G. Fu, Cheung W., "Designing a fourth-party e-commerce logistics center:a benefit,cost and risk analysis using AHP and ANP models,"Internet and Enterprise Management, vol. 1,no.1, pp.53-74,2003.

[6] S.C.FU,W.J.ZHANG, X.L.SHI, "Formation Mechanism of Information Risk in Supply Chain and Its Preventive Measure,” China Safety ScienceJournal,vol.14, no.11, pp.88-91, 2004.

[7] L-i. LI jun,X.Y.HUANG,X.T. ZHUANG, "Strategy of quality control in supply chain under double moral hazard condition,’Journal ofManagement Sciences in China, vol.8, no.1, pp.42-47,2005.

[8] Tu Jun,Huang Min, "Contract Design Based Quality Risk Management for Fourth Party Logistics," Information and Control, vol.43, no.3,pp.276-281, 2014.

[9] C.B.Chen,Q.Chen, "Study on the Credit Mechanisms between the Main Partners in the Fourth Party Logistics' Operation”, Journal of Industrial Technological Economics, vol.35, no.1, pp. 72-82, 2016.

[10] X.Xiong, J. Ma, W.J. Zhao, X.Y.Wang, J. Zhang, "Credit Risk Analysis of Supply Chain Finance," Nankai Business Review, vol. 12, no. 4, pp. 92-98, 2009.

[11] J.Hallikas, I.Karvonen, U.Pulkkinen, V.Virolainen, M.Tuominen, "Risk management process in supplier networks,’International Journal of Production Economics, vol. 90, no. 1, pp. 47-58, 2004. 